\title{
A Discussion on the Relationship and Mutual Effects of
}

\section{Knowledge Management and Information Management}

\author{
Baofeng Li \\ School of Management, Tianjin Polytechnic University \\ Tianjin 300387, China \\ Tel: 22-8395-1484Ｅ-mail: fengfengli88@126.com \\ Wenhua Song \\ School of Materials Science and Engineering, Tianjin Polytechnic University \\ Tianjin 300387, China \\ Shanghai Jiaotong University
}

\begin{abstract}
This paper begins with the consanguineous relationship between data, information and knowledge, and then talks about knowledge management and information management. According to their definitions and features we think that there is a close relationship and mutual promotion between the two. Information management offers a solid foundation to knowledge management while the latter proposes more requirements for the former. However, the two are not the same thing; they do have differences. For one thing, knowledge management is not the advanced stage of information management, as it didn't update from information management; for another, its sprouting is not for the defects of information management, but the necessity of knowledge-based economy development.
\end{abstract}

Keywords: Information, Knowledge, Knowledge management (KM), Information management (IM), Information technology (IT)

\section{Introduction}

With the development of knowledge economy and extension of trade globalization, KM started from scratch and has been developing in a gradual way until now. We can find IM from supermarkets to schools, enterprises to government offices. Nowadays, they are nearly familiar to everyone. In recent years, more and more researches on their relations have been being done. Some scholars consider that IM is the management of information while KM, as an advanced stage of IM, developed from inheriting the useful and discarding the useless of IM. However, the fact is not the same as they thought, IM isn't replaced by KM to some extent, and IM grows much faster than ever before. Therefore, it is important to make it clear that the relationship and differences between them are not allowed to ignore, which is beneficial for development of both IM and KM in the future.

\section{Data, information and knowledge}

Data are reflections and symbols of the real world objects' properties, and information, reflections of real objects, is the processed data which is gained by using all kinds of tools to collect, change, store, and then process all those original data. In essence, information is the description of objects, phenomena and laws both in nature and human society. However, they are not the same thing, and like the relationship between content and form, no matter human beings discover them or not, data are properties of objects, which exist objectively. On the contrary, information must be handled before they have some value. So information is the performances of human consciousnesses.

Knowledge is a summary and distillation of information and it can be passed to others and reproduced through study and sharing. Wang Zhijin said, Knowledge is a combination of knowledge and experience which are gained from the human practice of transforming the world, and it is an ideological matter, which can be generated, identified and used by the human brain alone. Neil Fleming thought that "An allocation of data is not information, a collection of 
information is not knowledge, a collection of knowledge is not wisdom, and a collection of wisdom is not truth". This means that information, knowledge, and wisdom are more than simply collections. Rather, the whole represents more than the sum of its parts and has a synergy of its own. In "Knowledge Management-emerging perspectives", the author studied the progressive relationship among data, information and knowledge from the perspective of cognitive science, as shown by figure 1 . He thought that the process, from data to information, and then knowledge, depended on human's awareness and understanding of data and information.

As is known to all, data is just a meaningless point in space and time, without reference to either space or time. That a collection of data is not information, as Neil indicated, implies that a collection of data for which there is no relation between the pieces of data is not information. The pieces of data may represent information, yet whether or not it is information depends on the understanding of the one perceiving the data and the knowledge of the interpreter. So information is quite simply an understanding of the relationships between pieces of data, or between pieces of data and other information.

\section{Insert Figure 1 about here}

While information entails an understanding of the relations between data, it generally does not provide a foundation for why the data is what it is, nor an indication as to how the data is likely to change over time. Information has a tendency to be relatively static in time and linear in nature.

When a pattern relation exists amidst the data and information, the pattern has the potential to represent knowledge. It only becomes knowledge, however, when one is able to realize and understand the patterns and their implications.

Bob Hallsworth believed that knowledge should be neither just Information nor data, and it should be available from wherever it is needed and to all those authorized to receive it. It means that data and information are a result from their being made full use of, combined with people's skills, abilities, thoughts, intuitions, responsibilities and power. However, Jerry Ash considered that knowledge is the people-oriented information which is analyzed, extracted and packaged by human brain. Therefore, knowledge is formed by the mankind' processing, together with their creation, of data $\&$ information. At the same time, the collection of data $\&$ information becomes more purposive because of the utilization of knowledge; it also puts forward new demands and directions for the development of IT. From data to information, and then to knowledge, the whole process is not separated, as it is developing along with people's improving cognitive abilities. In short, the situation of human knowledge affects, directly or indirectly, the depth, extent and accessible ways of data $\&$ information acquisition, as drawn by figure 2 :

\section{Insert Figure 2 about here}

\section{IM, KM and their relationships}

\subsection{Information management}

We may declare that information and knowledge have mutually reinforced and affected relationship which makes them inseparable. So the information-oriented IM and KM based on knowledge sharing \& use also have close relationship. In the late 1970s and early 1980s, the term "information management" was proposed, and it is almost familiar to everyone nowadays. It is thought that IM is a planning, budgeting, organization, conducting, and control process of information resources and other related resources, such as information equipment, facilities, IT, investment and staff, and so on. The process begins with communication between the users and system analysts, and then the analysts construe users' needs, collect \& convert information resources, organize, store, retrieve, transfer them, and finally make them meet the users' information demand. Information development and utilization is the core of IM, and what's more, the process of information resources exploitation and use constitutes the information resources life cycle, which is coherent with the mankind's recognizing and transforming the world.

\subsection{Knowledge management}

$\mathrm{KM}$ emerged along with the development of knowledge economy. Barth thought that KM is the process of creating, acquiring, and using knowledge with the purpose of reinforcing organization performances. Paul Ehrenfest, one of Delphi Corporation's initiators, also argued the meaning of KM was to provide the responsiveness and capability of innovation with the collective wisdom, and offered a new way for the knowledge sharing of explicit and tacit knowledge. D. A. Marchand and F. W. Horton, two American scholars, divided the development of information management into five phrases: control over substance, management of automation technology, information resource management, business competition analysis and intelligence and management of knowledge. Many domestic scholars also considered that KM is the advanced stage of IM, substituting for IM as a new management concept and method. Prof. Wu Jiapei was in favor of the view that KM is a new phrase of the development in IM, stressing the disparities between KM and the other former stages of IM. He held that KM required the connection among information \& information, information \& activities and information \&people, and that in the process of inter-personal communication, competitive advantage could be won over through the utilization of collective wisdom to innovate and sharing of 
information and knowledge including explicit and tacit knowledge. KM defined by Bai Bo and Zhang Xiaomei was a series of knowledge activities, also a kind of management activity to reinforce the capability of organization survival and competition, with the features of knowledge innovation that were conducted by making use of organization knowledge capital.

Qiu Junping and Duan Yufeng think that knowledge management is defined in two different ways_ — one is narrow, and the other broad. The narrow one is the management of knowledge per se, including management of knowledge creation, acquisition, processing, storage, dissemination and application. However, the broad one doesn't only contain the management of knowledge, but also management of a wide range of resources and intangible assets related to knowledge, which deals with the all-round management of knowledge organization, infrastructure, assets, and activities on the basis of the whole process. More often, the former is directed against the organizations (such as businesses), while the latter is generally carried out in the whole society. The purpose of the two is to be conducive to knowledge production, dissemination and application, thereby improving the overall quality and competitiveness of the main body and promoting socio -economic development ultimately. At present, the definition generally accepted at home is as follows: the so-called knowledge management is just is an acquisition of knowledge and skills within the entire enterprise and the strategies and processes in which knowledge and skills are distributed to help companies maximize the output in any place.

\subsection{The relationship between IM and $K M$}

In the architecture of IM, software and hardware provide an ideal initialization platform for information management, and IM offers KM the foundation and technical supports. KM and IM are complementary to each other and bear the relationship of division \& cooperation due to the continuous transformation and supplemental ties between knowledge and information, so that they can develop mutually and drive each other. The more developed knowledge-based economy and more expanding knowledge management, the more high-level information technology support needed, as well as more co-ordination offered by information management. Specifically, the close relationship can be seen as the following aspects:

(1) The two have mutually reinforcing effects

Even though KM and IM have different emphases, the purpose produced is basically identical. KM needs information management theory and technical supports; meanwhile, it raises more requests for IM, and the breakthroughs of theory research and practices in IM will provide new ideas and methods for KM. Enterprises have realized the importance of information, by which the cycle of new product development can be shortened, customers' needs understood more quickly and accurately, and this will make them have more market share and gain competitive advantages. Thus, enterprises don't only invest huge sums of money into high-tech internally to improve its management, but also highlight the more requirements of IM. However, the development of society is not static, and enterprises must rely on knowledge innovation in order to adapt to the competitive environment at all times.

(2) They both attach great importance to information and IT

There is no IM without information, as IM is based on information. Knowledge cannot exist without information because it provides raw material and source for knowledge innovation and the pursuit of KM goals. Knowledge will not be formed only by human's brain without information. We have to discuss deeply about information while doing research on how to use the laws of information, which is determined by internal relationship in them. IT, a research content of KM, is not only an important tool, but also are study and problem-solving methods. First of all, IT has not only accelerated the transmission speed and increased the breadth of access to information, but also made various kinds of information more sequential, which plays an active role in the knowledge innovation protection. What's more, modern information technologies break the space and time restrictions in information-exchange, making the communication form more vivid and intuitive, which is conducive to stimulating innovation and awareness of knowledge workers, as well as providing a more convenient and effective way for information-sharing. Finally, research related to intellectual properties rights will also be beneficial to the development of information technology.

\subsection{Differences between KM and IM}

\section{(1) Differences in management content}

Information management is about the collection, processing, retrieval \& communication, organization, control, and utilization of information, with the organization, management, preservation and service of literature and electronic information as the core, and management is mainly targeted at explicit knowledge. KM does not only involve explicit knowledge, but also tacit knowledge (personal knowledge, experience, competence \& skills, etc.) and the carrier of tacit knowledge_-management of people. Knowledge, created by human beings, is not the set of simple information. Likewise, only human beings can dominate in knowledge innovation, but a computer is just a tool which has a stronger ability to deal with information. Knowledge management effectively achieves the conversion between explicit knowledge and tacit knowledge, and materializes innovation in the process, which means that KM fully arouses 
people's initiatives and creativities. In another way, it boosts the efficiency of personnel management.

(2) Differences in management emphases

IM only extracts and processes substantial information simply, aimed at the allocation of information resources. It emphasizes techniques and tools of management, which pays great attention to the existing information management. Generally speaking, it does not have the function of information synthesis and knowledge extraction, because of the low information processing level and machinery pattern. But KM, a new management model, is directed against users' needs and actions in decision-making, which focuses on how to maximize the value of information $\&$ knowledge; innovations in the process of knowledge discovery, knowledge sharing, and knowledge utilization are also very important. Therefore, IM focuses on IT and the development and utilization of information while KM is concerned about the innovation.

(3) The different management objectives

Through the use of information technology, information management objectives are to improve the organization's capability to deal with information, and to actualize the collection, development, delivery, integration and use of information resources. It considers information as a kind of data which has an important role in the management and decision-making, and by means of improving the information technology application and level of information resource development, aggregates and organizes a wide range of information in different ways, in order to make it convenient for people to inquire and retrieve information by using computers, improve the efficiency and quality of individuals and organizations, and bring into play the value of information resources. On the other hand, knowledge management is people-centered, information-based, and knowledge innovation-oriented. Its origin is to regard knowledge as the most important strategic resource, and bring knowledge innovation \& sharing into reality via knowledge mining \& recombination, thereby improving the management and decision-making skills of organizations and developing the capital value of knowledge.

(4) The different mechanisms of operation

IM can minimize the cost through the decrease of time spent and the reduced amount of staff required. As a scarce resource, KM makes the best of the knowledge value to ensure the organization's core competitiveness with the help of knowledge sharing and transformation \& innovation.

We can conclude that they are mutually interdependent and promoted. For one thing, IM provides a wealth of information resources, and a powerful technology and information exchange platform for KM; for another, KM offers IM more development goals and higher requirements. But we cannot simply think of KM as upgraded from IM, since $\mathrm{KM}$ is not a management model aimed at improving inadequacy or defectiveness of IM, to say nothing of developing the useful and discard the useless of it.

\section{The impacts of IM on KM}

(1) IMis the foundation of KM. As is known to all, any management and decision-making can't go without the information, and knowledge management is no exception. What's more, there are much more requirements than ever before attached to the completeness, accuracy and simultaneity of the information. Therefore, good information management is the basis of knowledge management implementation.

(2) IM provides the basis of hardware and software for knowledge management. Enterprises with good functions of information management possess developed facilities of information collection system, which paves the way for the fact that information management is diffused into the four knowledge aspects. Advanced procedures of IM assist in the selection of useful knowledge and removal of data redundancy. There is a wide use by modern information management of electronic data and computers, and through the transition of information over the network, information collected can be standardized and recorded into enterprise database to facilitate inquiries and reduce the cost of information. The concept of modern information management toward corporation governance affects the corporate culture and staff perception, which is conducive to the implementation of knowledge management.

\section{The impacts of KM on IM}

Prof. Steve Clarke, in his paper the impacts of knowledge management on information management, gives us a simple introduction. He thought knowledge can be summarized as: acquisition, sharing, utilization, and measurement. The rise of knowledge management does not only enrich the content of the theory of enterprise management, but also puts forward new requirements for the enterprise management concept, pattern and information processing, and so on. So it is imperative for IM to renovate their tools such as management information system and integrate knowledge management function.

First of all, knowledge management has expanded the whole spectrum of information management objects. With the development of knowledge-based economy, the survival environment, scope and degree of market competition are changing all the time, so that the IM which originally dealt with only static information will not be able to continue to meet the challenging needs of enterprise development. This requires modern information management to strike a 
balance between dynamic and static information, as well as explicit and tacit knowledge.

In the next place, information management objectives can be optimized. The goal of knowledge management is to try to be able to transfer the right knowledge at the most appropriate time to the most appropriate person so that they can make the best decisions. Therefore, information management ought to utilize its information processing functions, explore useful information and create a favorable information exchange channel, so as to ensure that the correct and useful information can be transmitted to demanders in a timely and effective way.

Again, strategic decision-making and innovative services involved with information become more important. KM emphasizes decision-making in corporate strategy and planning, technology innovation, management innovation and knowledge innovation. This requires the development of IM pay attention to that trend as well. Therefore, enterprises should focus more on information services to meet corporate strategic decision-making and innovation of the random information demand; meanwhile, related agencies should adopt a variety of ways (information system integration, service integration, etc.) to develop the united collaborative services model and make full use of various knowledge resources, systems and services organizations to expand its service functions.

Forth, highlight the importance of "people". Knowledge management is "people-centered", which demands the development of IM also pay attention to that aspect. As we all know, how to develop a powerful system with stable performance and user-friendly operation interface, which can satisfy the different sectors' demands, must be considered.

Finally, more requirements need to be proposed for modern information management techniques. The main function of IM is to monitor the flow of enterprise funds, human resources and information of material stream, while knowledge management, characterized by integrity, continuity and dynamics, is mainly targeted at the "knowledge flow". These characteristics inevitably require that different management techniques be interdependent and coordinated. Information management needs a comprehensive utilization of support technologies, such as integrated knowledge management system, data warehouse \& mining, artificial intelligence technology, new retrieval technology, search engine \& network technology, component technology, and so on. And data warehouse and mining need to be established to ensure the transformation of information to knowledge, which can be shared in a timely way. This calls for enterprises to pay attention to the discovery and exploitation of information resources, information storage \& sharing, and exchange \& transfer. And the necessary technical support should be provided in the above-mentioned links for an implementation of knowledge discovery and sharing.

Under the background of the increasing development in the knowledge-based economy, only if IM and KM absorb the advantages of each other, improve their deficiencies, and strive to be innovative can they better adapt to the social development and meet the dramatically changing needs of mankind.

\section{Conclusions}

The process of transmitting data to information, and then information to knowledge, needs a steady deepening and continuous feedback. People use existing knowledge to screen data and information, and make some transformations and improvements to the available information technologies, targeted at meeting the ever-increasing individualized demand. IM pays more attention to the treatment methods of data and information, as well as the query and use of the existing knowledge, while KM stresses the initiative role of individuals in knowledge innovation, with more concerns piled on the sharing of knowledge. Its emergence is not directed against improvements in the defects of information management, but the product of the development of economic globalization, and it greatly enriches the connotation of enterprise management and enterprise information management model, so as to have a huge impact on information jobs. However, the emergence of knowledge management does not crowd out or replace information management, and contrarily promotes the development of information management to some extent.

Knowledge management and information management have many close relationships as well as differences. And distinguishing between disparities and connections of the two is of great significance to the future research and development of KM and IM.

\section{References}

(2006). Knowledge Management-Emerging Perspectives. [Online] Available: http://www.systems-thinking.org/kmgmt/kmgmt.htm. (9).

Bai, Bo \& Zhang, Xiaomei. (2001). Several Theoretical Issues about Knowledge management. Library and Information Service, (8):20-23.

Brian D. Newman. (2005). KM Forum Archives-The Early Days. [Online] Available: http://www.km-forum.org/what_is.htm.

Cheng, Gang. (2005). Innovation in Modern Enterprise Information Management. Hefei University of Technology Publishing House, 29-30. 
He, Shaohua. (2007). Information Management innovation under Knowledge Management Environment. Theory and Exploration, 30(3):292-295.

Hou, Xiaoli. (2008). Discussion on the Knowledge Management and Information Technology. Sci-Tech Information Development \& Economy, 18(32):78-79.

Lu, Gongping \& Wang Shanjian. (2000). From Information Management to Knowledge Management. Library and Information Service, (3):9-11.

Qiu, Junping, Duan, Yufeng \& Yue Ya. (1999). On knowledge Management and Information Management. The Journal of the library science in China, (11): 12-18.

Qiu, Junping. Knowledge Management Science. Scientific and Technical Documents Publishing House, 52-89.

Rivette K \& Kline D. (2000). Discovering New Value in Intellectual Property. Harvard Business Review, (1):54-66.

Steve, Clarke. (2006). The Impact of Knowledge Management on Information Management Practice. Information Management, 19(3):16-17.

Wang, Peilin. (2007). The Impact of Knowledge management on Information Management. Information and Documentation Services, (1):22-25.

Wang, Zhijin. (1998). From Information Organization to Knowledge Organization. Journal of the China Society for Scientific and Technical Information, 17(3): 230-234.

Wu, Jiapei. (1999). Understanding Correctly of Information and Knowledge and Issues related. Information Studies:

Theory \& Application, 22(1):1-4.

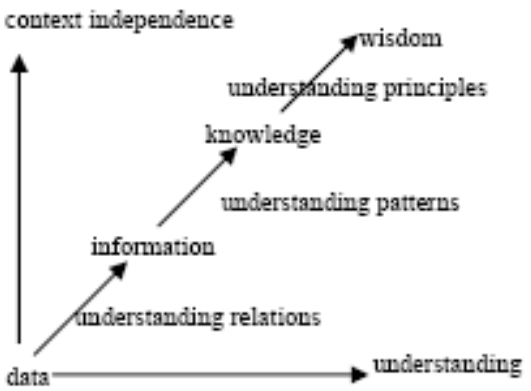

Figure 1. The relations between data, information and wisdom

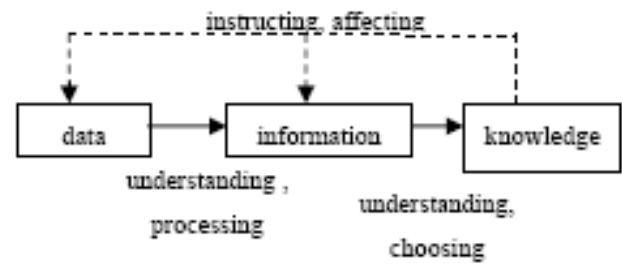

Figure 2. The mutual relation among data, information and knowledge 